\title{
Sulfonic acid-functionalized polyallylamine (sevelamer) as an efficient reusable strong solid acid catalyst for the synthesis of xanthenes derivatives
}

\author{
Xian-Liang Zhao ${ }^{* *} \mathbb{D}$, Makombe Shelton ${ }^{1}$ and Ke-Fang Yang ${ }^{2}$
}

\begin{abstract}
Sevelamer (polyallyamine resin)-supported sulfonic acid $\left(\mathrm{S}_{-} \mathrm{SO}_{3} \mathrm{H}\right)$ has been prepared from the reaction of sevelamer with chlorosulfonic acid and characterized using FT-IR spectroscopy, scanning electronmicroscopy (SEM) and thermogravimetric analysis (TGA). The catalytic activity of $\mathrm{S}_{-} \mathrm{SO}_{3} \mathrm{H}$ was investigated in the synthesis of 1,8-dioxo-octahydroxanthene derivatives. All of the reactions were fast and gave excellent yields. The catalyst was easily recovered and reused for 5 runs without significant loss of its catalytic activity.
\end{abstract}

Keywords: Sevelamer, Sulfonic acid, 1,8-Dioxo-octahydroxanthene, Recycle, Water

\section{Introduction}

Heterogeneous catalysis involving functional polymers has been very important over the past few decades [1-3]. Catalysts immobilized on a functional polymer support shows efficiency strategy for the isolation and catalyst recycling, leading to economic and environmental advantages $[4,5]$.

The most commonly used polymer-supports involves polystyrene cross-linked with divinylbenzene (PS/DVB) [6-8]. However, there are some drawbacks to PS/DVB. The number of chemical modification reactions, such as chloromethylation, sulfonation that can be carried out to introduce functional groups onto the polystyrene (PS)based beads are limited and the reactions themselves may be difficult to control. On the other hand, the induced functional groups are limited and reduce the number of catalytic sites. It's useful that functional polymers contain reactive groups that can be used directly for the further introduction of functional groups. The amount of induced functional groups can be easily controlled.

\footnotetext{
*Correspondence: xlzhao@iccas.ac.cn

1 School of Biological and Chemical Engineering, Zhejiang University of Science and Technology, Hangzhou 310023, People's Republic of China Full list of author information is available at the end of the article
}

Sevelamer is a co-polymer of epichlorohydrin and polyallylamine [9]. Sevelamer is an environmentally friendly solid material with excellent mechanical strength and stability. This compound contains abundant amine groups, which can be easily transformed into various functionality.

The use of solid acids in organic synthesis and the industrial manufacture of materials is of increasing importance [10]. Heterogeneous acid catalysts such as solid acid zeoilte, solid superacid sulfated zirconia and Nafion have been explored in both organic synthesis and large scale industry. Polymer supported acids, such as polystyrene resin and perfluorinated ion exchange polymers, have also been prepared and widely used in organic synthesis [11-13]. These catalysts are suitable for a variety of synthetic conditions. However, they are associated with one or more disadvantages such as lower reactivity, the use large quantities of the solid support and not being suitable for reactions conducted in aqueous media.

In the past decade, xanthene and its derivatives has been widely used in pharmaceuticals, drug discovery, dyes, fluorescent materials and biochemistry. Xanthenes, especially 1,8-dioxo-octahydroxanthenes, are prepared using a range of different methods, due to their wide range of synthetic, industrial and 
pharmacological applications [14-18]. Various catalysts have been used for the preparation of these xanthenes. A wide range of catalysts such as MCM-41- $\mathrm{SO}_{3} \mathrm{H}$ [19], $\mathrm{SbCl}_{3} / \mathrm{SiO}_{2}$ [20], $p$-dodecylbenzene sulfonic acid [21], triethylbenzylammonium chloride [22], $\beta$-cyclodextrin $\mathrm{SO}_{3} \mathrm{H}$ [23], Amberlyst-15 [24], diammonium hydrogen phosphate [25] and nano- $\mathrm{TiO}_{2}$ [26] have been used for the preparation of 1,8-dioxo-octahydroxanthenes. On the other hand, there have been several reports describing the use of $\mathrm{SO}_{3} \mathrm{H}$ immobilized on polymers towards the synthesis of 1,8-dioxo-octahydroxanthenes. However, many of these methods suffer from disadvantages such as low yields, long reaction times, the use of harmful volatile organic solvents and tedious work-ups.

Recently, we have focused our attention on the use of polymeric catalysts as recyclable catalysts in organic synthesis in environmentally sustainable chemistry [27]. Functional polymers used as the solid support are very important for the definition of efficient synthetic procedures especially when safer reaction media, ecofriendly alternatives to organic solvents or solvent-free conditions (SolFC) are used.

\section{Experimental}

\section{Instruments}

TGA was carried out on a Mettler-Toledo 851E instrument. ${ }^{1} \mathrm{H}$ NMR spectra were recorded on a $400 \mathrm{MHz}$ spectrometer (Varian, Palo Alto, USA) in DMSO solution. Chemical shift values are given in parts per million. IR spectra were recorded on a Perkin Elmer (model: spectrum BX) FT-IR Spectrometer using $\mathrm{KBr}$ pellets.

\section{Preparation of polyallylamine hydrochloride}

Allylamine $(15.0 \mathrm{~g})$ was slowly added to concentrated $\mathrm{HCl}(26.8 \mathrm{~g})$ maintaining the temperature below $10{ }^{\circ} \mathrm{C}$. Nitrogen gas was introduced into the flask after $30 \mathrm{~min}$ and the solution was heated at $50{ }^{\circ} \mathrm{C}$. Afterwards, 2,2'-diamidinyl-2,2'-azo-propane dihydrochloride $(1.0 \mathrm{~g})$ was added to the solution. The reaction mixture was stirred at $50{ }^{\circ} \mathrm{C}$ for $24 \mathrm{~h}$. A second portion of 2,2'-diamidinyl-2,2'-azo-propane dihydrochloride (1.0 g) was then added to the solution. The reaction mixture was maintained for another $24 \mathrm{~h}$ at $50{ }^{\circ} \mathrm{C}$. The pale yellow, transparent and viscous solution obtained in this process was added into a large amount of methanol and a white polymer precipitate was subsequently produced. This precipitate was filtered and extracted with methanol using a Soxhlet extractor for $10 \mathrm{~h}$. After being dried at $50{ }^{\circ} \mathrm{C}$, polyallylamine hydrochloride was obtained (15.6 g).

\section{Typical procedure for the preparation of support s}

Polyallylamine hydrochloride $(5.0 \mathrm{~g})$ was dissolved in water $(75.0 \mathrm{~mL})$ to obtain a clear solution at $30{ }^{\circ} \mathrm{C}$. The solution was further cooled to $10{ }^{\circ} \mathrm{C}$. Then, $\mathrm{NaOH}$ (1.38 g) was added to the solution at $10{ }^{\circ} \mathrm{C}$ and stirred for $30 \mathrm{~min}$. Then, $40 \mathrm{~mL}$ of toluene and SPAN-85 $(0.2 \mathrm{~g})$ were added to the mixture at $10{ }^{\circ} \mathrm{C}$. The reaction mixture was maintained for another $30 \mathrm{~min}$ at $10{ }^{\circ} \mathrm{C}$. The temperature was then increased to $55{ }^{\circ} \mathrm{C}$ and maintained at this temperature for $15 \mathrm{~min}$. Afterwards, epichlorohydrin $(0.45 \mathrm{~g})$ was added to the reaction mixture at $55{ }^{\circ} \mathrm{C}$ and maintained at this temperature for $3 \mathrm{~h}$. The reaction mixture was cooled to room temperature. Sevelamer hydrochloride was then filtered, washed with water and dried in vacuo. The compound was then soaked in $\mathrm{NaOH}$ solution $(10.0 \mathrm{~g}, 10 \% \mathrm{w} / \mathrm{v})$ at room temperature for $24 \mathrm{~h}$. The product was filtered and washed with hot water until it became $\mathrm{pH}$ neutral. Finally, the product was dried at $60{ }^{\circ} \mathrm{C}$ for $12 \mathrm{~h}$ under vacuum. S (3.22 g, 94\%) was obtained as a pale-yellow solid.

\section{Preparation of $\mathrm{S}_{-} \mathrm{SO}_{3} \mathrm{H}$}

A suspension of sevelamer $(4.0 \mathrm{~g})$ and $\mathrm{Na}_{2} \mathrm{CO}_{3}(7.35 \mathrm{~g})$ in dry $\mathrm{CH}_{2} \mathrm{Cl}_{2}(20 \mathrm{~mL})$ was added to a suction flask. Then, chlorosulfonic acid $(3.0 \mathrm{~mL}, 30 \mathrm{mmol})$ was added dropwise over a period of $15 \mathrm{~min}$ at room temperature while the mixture was stirred slowly at room temperature. After the addition was complete, the mixture was stirred for $12 \mathrm{~h}$. Then, the $\mathrm{CH}_{2} \mathrm{Cl}_{2}$ was removed by filtration under reduced pressure and the solid powder dissolved in water $(200.0 \mathrm{~mL})$. The mixture was filtered again. The solid powder was washed with water, then soaked in $\mathrm{H}_{2} \mathrm{SO}_{4}$ solution (10.0 g, $\left.10 \% \mathrm{v} / \mathrm{v}\right)$ at room temperature for $24 \mathrm{~h}$. The product was filtered and washed with water until it became $\mathrm{pH}$ neutral. Finally, the product was dried at $70{ }^{\circ} \mathrm{C}$ for $12 \mathrm{~h}$ under vacuum. A yellow solid of polyallylamine-supported sulfonic acid was obtained $(6.1 \mathrm{~g})$.

\section{Results and discussion Preparation of $\mathrm{S}-\mathrm{SO}_{3} \mathrm{H}$}

The synthetic strategy used to prepare $\mathrm{S}-\mathrm{SO}_{3} \mathrm{H}$ is shown in Scheme 1. At first, sevelamer was synthesized according to our previous work. Then, sevelamer was used to support $\mathrm{SO}_{3} \mathrm{H}$.

\section{Catalyst characterization \\ Scanning electron microscopy}

Scanning electron micrographs which shows the preparation of sevelamer support are reported in Fig. 1. Resin sevelamer (Fig. 1a) shows a fine and uniform surface 

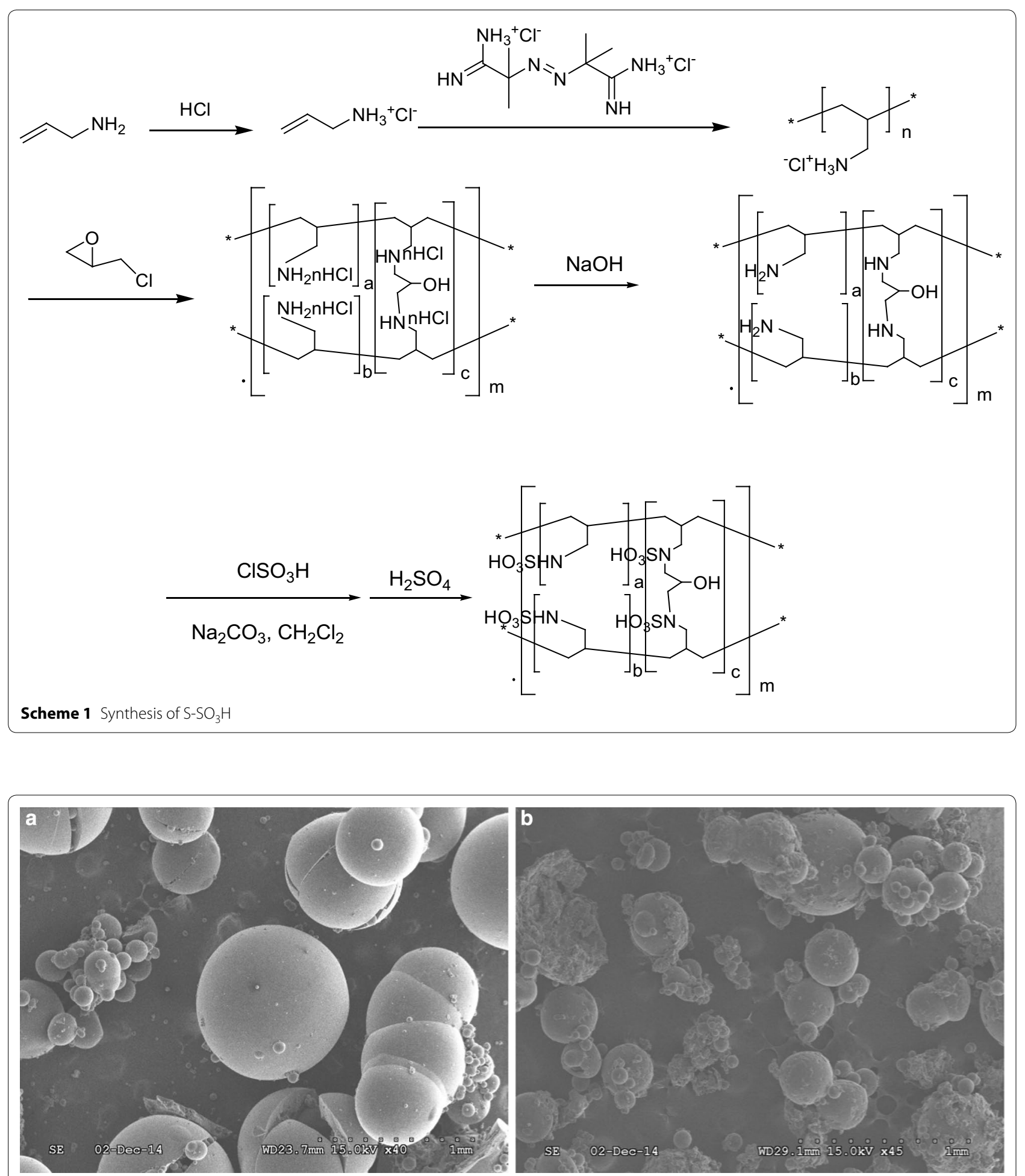

Fig. $1 \mathrm{SEM}$ image of resin sevelamer (a) and resin $\mathrm{S}_{-} \mathrm{SO}_{3} \mathrm{H}(\mathbf{b})$. a sevelamer before supported by $\mathrm{ClSO}_{3} \mathrm{H}$, $\mathbf{b}$ sevelamer after supported by $\mathrm{CISO}_{3} \mathrm{H}$

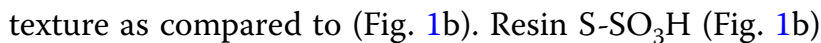
show rough contamination with fragments on its surface.
FT-IR spectroscopy

The FT-IR spectra of sevelamer and $\mathrm{S}-\mathrm{SO}_{3} \mathrm{H}$ are shown in Fig. 2. The absorbance bands ranging between 

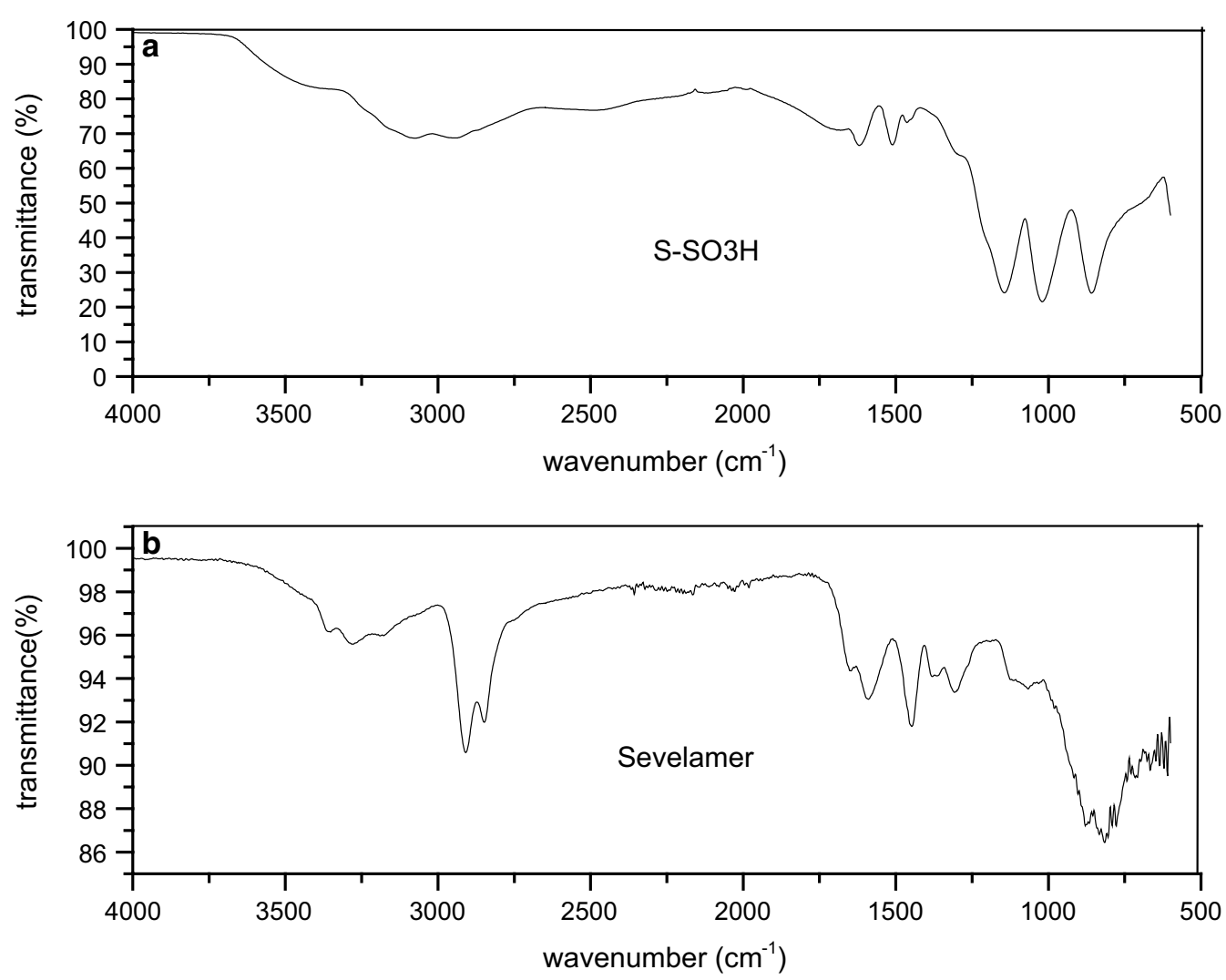

Fig. $2 \mathrm{FTIR}$ spectra of resin sevelamer (b) and resin $\mathrm{S}_{-} \mathrm{SO}_{3} \mathrm{H}(\mathbf{a})$. a sevelamer after supported by $\mathrm{ClSO}_{3} \mathrm{H}$, $\mathbf{b}$ sevelamer before supported by $\mathrm{ClSO}{ }_{3} \mathrm{H}$

3200-3500 $\mathrm{cm}^{-1}$ were shows acid adsorption (Fig. 2a) and amine (Fig. 2b). Strong peak at $1144 \mathrm{~cm}^{-1}$ represents the $\mathrm{S}-\mathrm{N}$ stretching (the weak band observed at the same frequency in the sevelamer spectrum) was notable. In Fig. 2a, the absorption range at 1176-1284 and 1006$1088 \mathrm{~cm}^{-1}$ shows the possibility of $\mathrm{O}-\mathrm{S}-\mathrm{O}$ asymmetric and symmetric stretching modes, respectively and the $\mathrm{S} \backslash \mathrm{O}$ stretching mode lies at $675-852 \mathrm{~cm}^{-1}$ showing the presence of the sulfonic acid functional group, which was consistent with the reported IR spectra for $\mathrm{SO}_{3} \mathrm{H}$.

\section{Thermogravimetric analysis}

The thermogravimetric analysis (TGA) of $\mathrm{S}_{-} \mathrm{SO}_{3} \mathrm{H}$ in comparison with sevelamer is shown in Fig. 3. Weight loss of (5 wt\%) below $100{ }^{\circ} \mathrm{C}$ for sevelamer is displayed by the TGA curves in (Fig. 3a), which corresponds to the loss of physically adsorbed water. The ash content was only $1.6 \%$. In the TGA curve for $\mathrm{S}_{-} \mathrm{SO}_{3} \mathrm{H}$ (Fig. $3 \mathrm{~b}$ ), three regions corresponding to different mass lose ranges exist. The first mass loss region was below $150{ }^{\circ} \mathrm{C}$ and was attributed to the loss of trapped water from the catalyst. A mass loss of approximately $10 \mathrm{wt} \%$ occurred between 100 and $200{ }^{\circ} \mathrm{C}$, which was related to the slow mass loss of $\mathrm{SO}_{3} \mathrm{H}$ groups. Finally, a mass loss of approximately 50

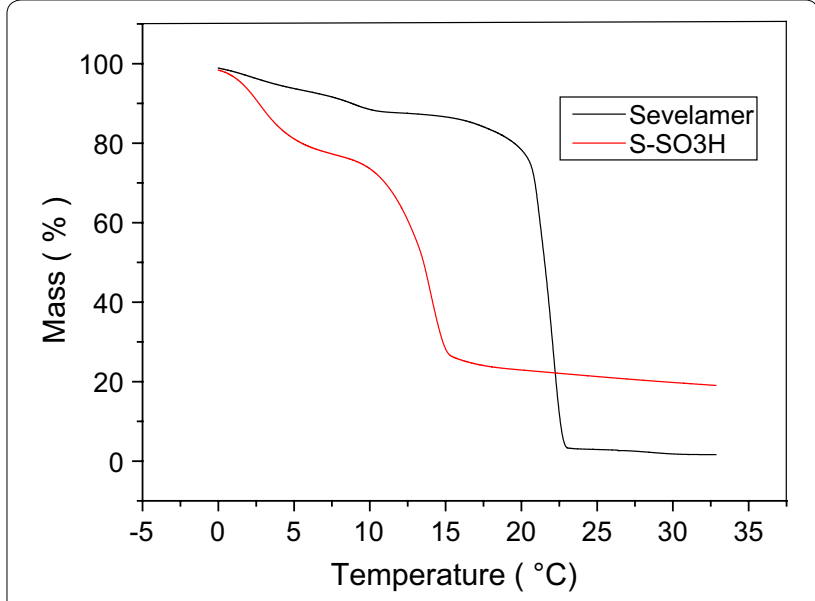

Fig. $3 \mathrm{TGA}$ of resin sevelamer and resin $\mathrm{S}_{-} \mathrm{SO}_{3} \mathrm{H}$

wt\% occurred between 240 and $300{ }^{\circ} \mathrm{C}$, which was related to the sudden mass loss of the resin. The ash content was up to $20 \%$. This result shows the $\mathrm{S}-\mathrm{SO}_{3} \mathrm{H}$ easily turns into carbon or sulfate slats under the acidic atmosphere and high temperature. Also, from the TGA results, it was found that sevelamer has a greater thermal stability 
than $\mathrm{S}-\mathrm{SO}_{3} \mathrm{H}$. However, $\mathrm{S}-\mathrm{SO}_{3} \mathrm{H}$ can still be safely used in organic reactions at temperatures in the range of $0-120^{\circ} \mathrm{C}$.

\section{BET surface area analysis}

The surface area of the catalysts is an important factor influencing the catalytic activity. The surface area of polymer resin and catalyst was determined using the nitrogen gas adsorption method. BET surface area of sevelamer $\left(2.668 \mathrm{~m}^{2} \mathrm{~g}^{-1}\right)$ is almost same as the surface area of $\mathrm{S}-\mathrm{SO}_{3} \mathrm{H}\left(3.010 \mathrm{~m}^{2} \mathrm{~g}^{-1}\right)$.

\section{Application of $\mathrm{S}_{-} \mathrm{SO}_{3} \mathrm{H}$ as an efficient catalyst in organic reactions}

The studies demonstrated for the use inexpensive and environmentally friendly S-supported sulfonic acid $\left(\mathrm{S}-\mathrm{SO}_{3} \mathrm{H}\right)$ as a heterogeneous solid acid catalyst shows very satisfactory results. In the present work, $\mathrm{S}-\mathrm{SO}_{3} \mathrm{H}$ was easily prepared and used as a highly efficient, heterogeneous, reusable and inexpensive solid acid catalyst for synthesis of 1,8-dioxo-octahydroxanthene derivatives.

The 1,8-dioxo-octahydroxanthenes are an important structural unit in many natural compounds with biological and pharmaceutical activities. Water is considered to be an environmentally benign solvent. Therefore, the reaction of benzylaldehyde and 1,3-cyclohexanedione was selected as a model reaction to screen the experimental conditions in aqueous media. Reaction progress was monitored by thin-layer chromatography. To examine the temperature effects, the model reaction was carried out with catalyst loadings of $0.010 \mathrm{~g} \mathrm{~S}-\mathrm{SO}_{3} \mathrm{H}$ in aqueous media. The reaction proceeded smoothly at room temperature, but the product was obtained in $73 \%$ in $120 \mathrm{~min}$ (Table 1, entry 1). With an increase in temperature, the reaction time was significantly decreased. This reaction was completed in $30 \mathrm{~min}$ at $90{ }^{\circ} \mathrm{C}$ (Table 1 , entry 4). To justify the efficiency of the $\mathrm{S}_{-} \mathrm{SO}_{3} \mathrm{H}$, the model reaction was carried out in the presence of different amounts of $\mathrm{S}-\mathrm{SO}_{3} \mathrm{H}$ in aqueous media. It was found that the product 3a was formed in high yields with catalyst loadings of $0.0100 \mathrm{~g}$ (Table 1, entry 8). A higher amount of catalyst did not accelerate the reaction time or promote the reaction yield (Table 1, entry 9). A lower yield of product 3a was obtained with a lower amount of catalyst and in a reaction time of $8 \mathrm{~h}$ (Table 1 , entry 5 ).

After optimizing the conditions, the scope of the method was successfully studied using a variety of aldehydes in water. Both electron-rich and electron-deficient aromatic aldehydes worked well, giving high yields of the desired products. Electron-deficient aldehydes needed shorter reaction times and gave somewhat higher yields than their electron-rich counterparts (Table 2,

Table 1 Temperature and catalyst amount for the synthesis of 1,8-dioxo-octahydroxanthene

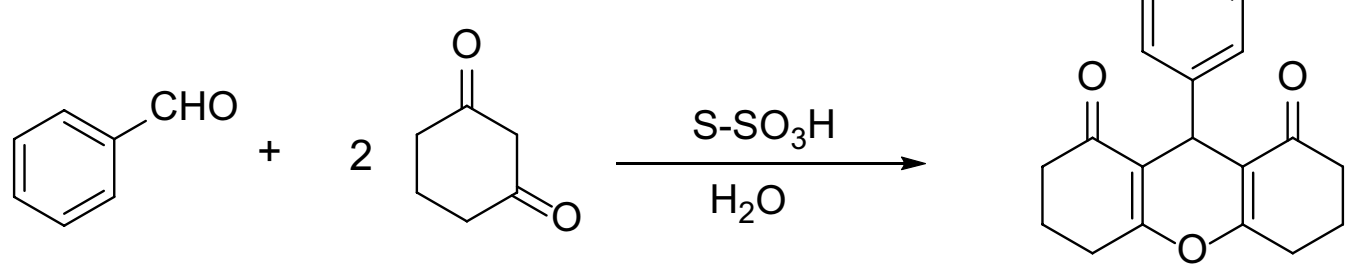

$1 a$

$2 a$

3a

\begin{tabular}{lllll}
\hline Entry & $\mathbf{T}\left({ }^{\circ} \mathbf{C}\right)$ & Amount of catalyst (g) & Time (min) & Yield (\%) \\
\hline 1 & 25 & 0.0100 & 120 & 73 \\
2 & 50 & 0.0100 & 120 & 82 \\
3 & 70 & 0.0100 & 90 & 91 \\
4 & 90 & 0.0100 & 30 & 94 \\
5 & 90 & - & $12 \mathrm{~h}$ & 31 \\
6 & 90 & 0.0010 & $8 \mathrm{~h}$ & 84 \\
7 & 90 & 0.0050 & 60 & 90 \\
8 & 90 & 0.0100 & 30 & 94 \\
9 & 90 & 0.0150 & 30 & 95 \\
\hline
\end{tabular}

Reaction conditions: $\mathbf{1 a}(1.0 \mathrm{mmol}), \mathbf{2 a}(2.0 \mathrm{mmol}), \mathrm{S}-\mathrm{SO}_{3} \mathrm{H}(10 \mathrm{mg})$, water $(1.0 \mathrm{~mL}), 90^{\circ} \mathrm{C}$

a Isolated yield 
Table 2 Substrate scope of reaction between various aromatic aldehydes and cyclohexanedione

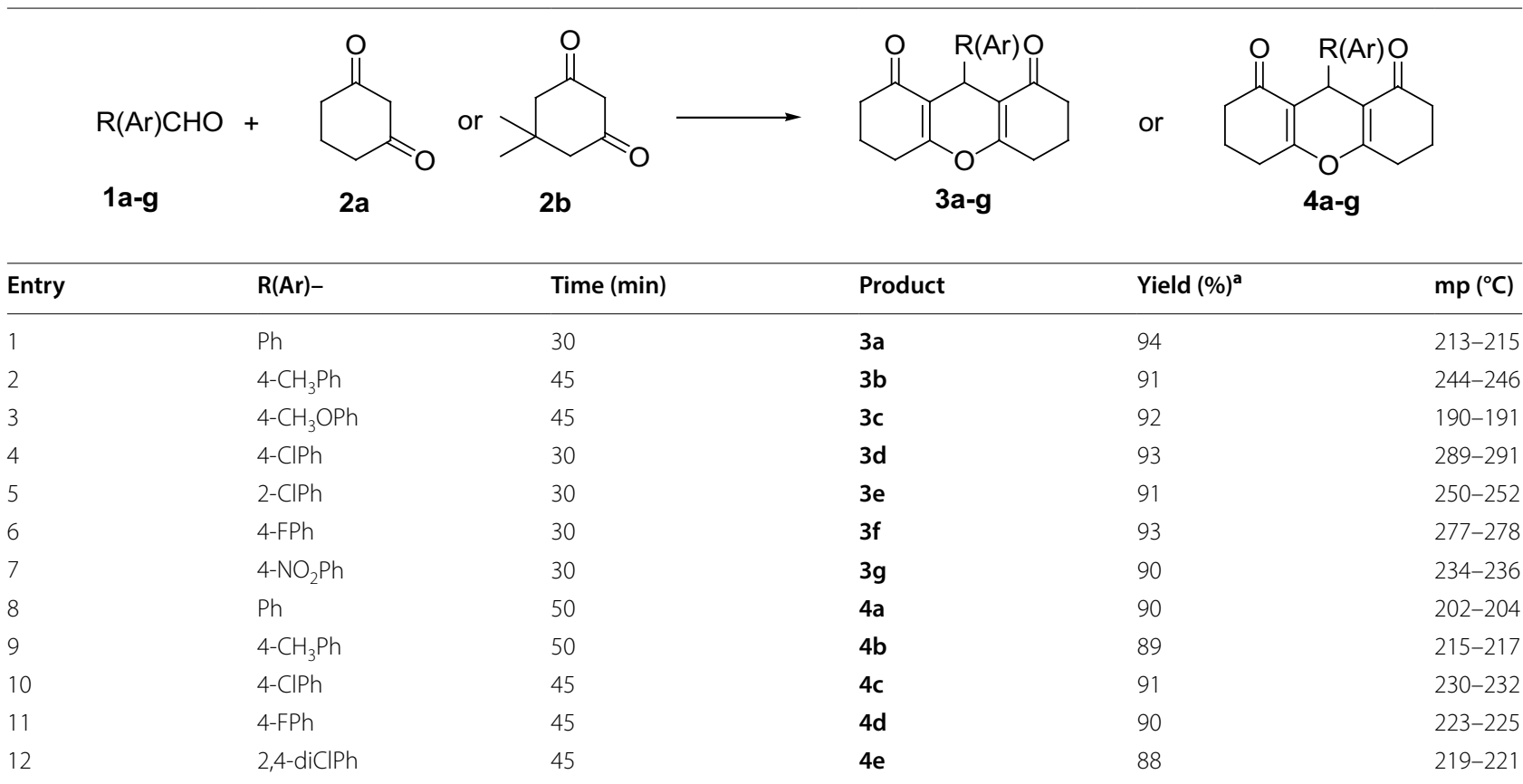

Reaction conditions: $1(1.0 \mathrm{mmol}), \mathbf{2}(2.0 \mathrm{mmol}), \mathrm{S}-\mathrm{SO}_{3} \mathrm{H}(10 \mathrm{mg})$, water $(1.0 \mathrm{~mL}), 90^{\circ} \mathrm{C}$

a Isolated yield

entries 1-6). In almost all cases, the reactions proceeded smoothly within 30-50 min.

Five consecutive syntheses of 1,8-dioxo-octahydroxanthene was done to demonstrate the easy recyclability using the recovered $\mathbf{S}-\mathbf{S O}_{3} \mathbf{H}$ catalyst. Once product 3a was filtered from the reaction mixture, the $\mathbf{S}-\mathbf{S O}_{3} \mathbf{H}$ catalyst was used directly in another cycle without drying. The catalyst showed no appreciable loss in activity. All reactions were completed in $30 \mathrm{~min}$ and the desired product was obtained in $91-94 \%$ yield.

\section{Conclusion}

Sevelamer (polyallyamine resin)-supported sulfonic acid $\left(\mathrm{S}-\mathrm{SO}_{3} \mathrm{H}\right)$ was used as an efficient heterogeneous catalyst for the synthesis of 1,8-dioxo-octahydroxanthene derivatives in summary. This catalyst could be easily separated from the reaction mixture and directly reused after a simple extraction step. The catalyst was recycled for seven consecutive cycles without any obvious loss in its catalytic activity. As a good heterogeneous solid acid, $\mathrm{S}-\mathrm{SO}_{3} \mathrm{H}$ is stable in air, easy to prepare and can be recovered easily. The scope and synthetic applications of the $\mathrm{S}_{-} \mathrm{SO}_{3} \mathrm{H}$ catalyst are currently under investigation in our laboratory.

\section{Acknowledgements}

We gratefully acknowledge financial support by the National Natural Science Foundation of China (Nos. 21302168, 51203037).
Authors' contributions

ZXL, YKF conceived and designed the experiments; ZXL and MS performed the experiments; YKF analyzed the data; ZXL wrote the paper. All authors read and approved the final manuscript.

Funding

This study was financially supported by the National Natural Science Foundation of China (Nos. 21302168, 51203037).

Availability of data and materials

All data are fully available without restriction.

Competing interests

The authors declare that they have no competing interests.

Author details

${ }^{1}$ School of Biological and Chemical Engineering, Zhejiang University of Science and Technology, Hangzhou 310023, People's Republic of China. ${ }^{2}$ Key Laboratory of Organosilicon Chemistry and Material Technology of Ministry of Education, Hangzhou Normal University, Hangzhou 310012, China.

Received: 17 November 2018 Accepted: 2 July 2019

Published online: 26 July 2019

References

1. Lu J, Toy PH (2009) Organic polymer supports for synthesis and for reagent and catalyst immobilization. Chem Rev 109:815-838

2. Zaheri HM, Javanshir S, Hemmati B, Dolatkhah Z, Fardpour M (2018) Magnetic core-shell Carrageenan moss $/ \mathrm{Fe}_{3} \mathrm{O}_{4}$ : a polysaccharide-based metallic nanoparticles for synthesis of pyrimidinone derivatives via Biginelli reaction. Chem Cent J 12:108-118

3. Aravind A, George S, Kumar S (2012) Remarkable influence of microwave heating on Morita-baylis-Hillman reaction in PEG-200. Chem Cent J 6:30-35 
4. Akelah A, Sherrington DC (1981) Application of functionalized polymers in organic synthesis. Chem Rev 81:557-587

5. Sherrington DC, Hodge P (1988) Synthesis and separation using functional polymers. Wiley, Chichester

6. Regen SL (1975) Triphase catalysis. J Am Chem Soc 97:5956

7. Regen SL (1979) Triphase catalysis. Angew Chem Int Ed 18:421-429

8. Sherrington C (1998) Preparation, structure and morphology of polymer supports. Chem Commun 30:2275-2286

9. Kioussis D, Smith D, Kofinas P (2001) Ammonium perchlorate-binding poly(allylamine hydrochloride) hydrogels for wastewater remediation. J Appl Polym Sci 80:2073-2083

10. Hattori H, Ono Y (2015) Solid acid catalysis: from fundamentals to applications. Pan Stanford, San Antonio

11. Okayasu T, Saito K, Nishide H, Hearn MTW (2009) Preparation of a novel poly(vinylsulfonic acid)-grafted solid phase acid catalyst and its use in esterification reactions. Chem Commun 31:4708-4710

12. Heitner-Wirguin C (1996) Recent advances in perfluorinated ionomer membranes: structure, properties and applications. J Membr Sci 120:1

13. Mauritz KA, Moore RB (2004) State of understanding of nafion. Chem Rev 104:4535

14. Feringa BL (2007) The art of building small: from molecular switches to molecular motors. J Org Chem 72:6635-6652

15. Kitahara Y, Tanaka K (2002) Synthesis, crystal structure and properties of thiaheterohelicenes containing phenolic hydroxy functions. Chem Commun 9:932-933

16. Ahmad M, King TA, Ko DK, Cha BH, Lee J (2002) Performance and photostability of xanthene and pyrromethene laser dyes in sol-gel phases. J Phys D Appl Phys 35:1473-1476

17. Knight CG, Stephens T (1989) Xanthene-dye-labelled phosphatidylethanolamines as probes of interfacial pH. Studies in phospholipid vesicles. $J$ Biochem. 258(258):683-687

18. Shaheen F, Ahmad M, Khan SN, Hussain SS, Anjum S, Tashkhodjaev B (2006) New a-glucosidase inhibitors and antibacterial compounds from Myrtus communis L. Eur J Org Chem. 10:2371-2377

19. Rostamizadeh S, Amani AM, Mahdavinia GH, Amiri G, Sepehrian H (2010) Ultrasound promoted rapid and green synthesis of 1,8-dioxo-octahydroxanthenes derivatives using nanosized MCM-41$\mathrm{SO}_{3} \mathrm{H}$ as a nanoreactor, nanocatalyst in aqueous media. Ultrason Sonochem 17:306-309

20. Zhang $\mathrm{ZH}$, Liu YH (2008) Efficient photocatalytic $\mathrm{H}_{2}$ production under visible light irradiation over Ni doped Cd1-xZnxS microsphere photocatalysts. Catal Commun 9:1715-1719

21. Jin TS, Zhang JS, Xiao JC, Wang AQ, Lix TS (2004) A clean synthesis of 1,8-dioxo-octahydroxanthene derivatives catalyzed by p-dodecylbenezenesulfonic acid in aqueous media. Synlett 5:866-870

22. Wang XS, Shi DQ, Li YL, Chen H, Wei XY, Zong ZM (2005) Improved and highly versatile synthesis of 5-aryltropones. Synth Commun 35:97-104

23. Kokkirala S, Sabbavarapu NM, Yadavalli VDN (2011) $\beta$-Cyclodextrin mediated synthesis of 1,8-dioxooctahydroxanthenes in water. Eur J Chem 2:272-275

24. Das B, Thirupathi P, Mahender I, Reddy VS, Rao YK, Mol J (2006) Amberlyst-15: an efficient reusable heterogeneous catalyst for the synthesis of 1,8-dioxo-octahydroxanthenes and 1,8-dioxo-decahydroacridines. Catal A-Chem 247:233-239

25. Darvish F, Balalaei S, Chadegani F, Salehi P (2007) Diammonium hydrogen phosphate as a neutral and efficient catalyst for synthesis of 1,8-dioxooctahydroxanthene derivatives in aqueous media. Synth Commun 37:1059-1067

26. Khazaei A, Moosavi-Zare AR, Mohammadi Z, Zare A, Khakyzadeh V, Darvishi G (2013) Efficient preparation of 9-aryl-1,8-dioxo-octahydroxanth, enes catalyzed by nano- $-\mathrm{TiO}_{2}$ with high recyclability. RSC Adv. 3:1323-1326

27. Zhao XL, Yang KF, Zhang YP, Xu LW (2014) Sevelamer as an efficient and reusable heterogeneous catalyst for the Knoevenagel reaction in water. Chin Chem Lett 25(25):1141-1144

\section{Publisher's Note}

Springer Nature remains neutral with regard to jurisdictional claims in published maps and institutional affiliations.
Ready to submit your research? Choose BMC and benefit from:

- fast, convenient online submission

- thorough peer review by experienced researchers in your field

- rapid publication on acceptance

- support for research data, including large and complex data types

- gold Open Access which fosters wider collaboration and increased citations

- maximum visibility for your research: over $100 \mathrm{M}$ website views per year

At $\mathrm{BMC}$, research is always in progress.

Learn more biomedcentral.com/submissions 